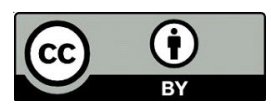

UDC 342.7

LBC 67.0
Submitted: 21.05.2021

Accepted: 14.06.2021

\title{
THE ROLE OF INCENTIVE SANCTIONS IN THE PROCESS OF LEGAL REGULATION ${ }^{1}$
}

\author{
Roman S. Markunin \\ Saratov State Law Academy, Saratov, Russian Federation
}

\author{
Alexandra A. Musatkina \\ Togliatti State University, Tolyatti, Russian Federation
}

\begin{abstract}
Introduction: the measures of encouragement, at the present stage of development of the legal state, occupy a key place among the instruments of legal stimulation of subjects of legal relations to commit lawful and socially demanded actions. For this reason, the scientific interest in finding the most effective options for their normative consolidation in the current legislative framework is quite understandable. Purpose: to determine the features and level of influence of incentive sanctions on the process of regulating legal relations in the company. Methods: the methodological framework for the paper consists of some methods of cognition, among which one can distinguish: formal-legal, systemic, comparative law, etc. Results: incentive sanctions contribute to the formation of a correct system of values in the subject of legal relations, which leads to the commission of exemplary actions, socially demanded acts of behavior. Conclusions: according to the results of the study, it can be argued that the legal regulation of incentive measures in the current legislation is fragmentary. The insufficient regulatory consolidation of the incentive procedure leads to the destabilization of public relations and a decrease in the effectiveness of the incentive function as a whole.
\end{abstract}

Key words: sanction, encouragement, incentive, benefits, discretionary powers, state award.

Citation. Markunin R.S., Musatkina A.A. The Role of Incentive Sanctions in the Process of Legal Regulation. Legal Concept $=$ Pravovaya paradigma, 2021, vol. 20, no. 3, pp. 47-52. (in Russian). DOI: https://doi.org/10.15688/lc.jvolsu.2021.3.8

УДК 342.7

ББК 67.0
Дата поступления статьи: 21.05.2021

Дата принятия статьи: 14.06.2021

\section{РОЛЬ ПООЩРИТЕЛЬНЫХ САНКЦИЙ В ПРОЦЕССЕ ПРАВОВОГО РЕГУЛИРОВАНИЯ ${ }^{1}$}

\author{
Роман Сергеевич Маркунин \\ Саратовская государственная юридическая академия, г. Саратов, Российская Федерация \\ Александра Анатольевна Мусаткина \\ Тольяттинский государственный университет, г. Тольятти, Российская Федерация
}

\begin{abstract}
Введение: меры поощрения на современном этапе развития правовой государственности занимают ключевое место среди инструментов правового стимулирования субъектов правоотношений на совершение правомерных и социально востребованных действий. По этой причине вполне объясним научный интерес к поиску наиболее эффективных вариантов их нормативного закрепления в действующей законодательЕ ной базе. Цель: определить особенности и уровень влияния поощрительных санкций на процесс регулирования правоотношений в обществе. Методы: методологическую основу статьи составил ряд методов познания, среди которых можно выделить формально-юридический, системный, сравнительно-правовой и др. Результаты: поощрительные санкции способствуют формированию у субъекта правоотношений верной системы ценностей, которая приводит к совершению образцовых, социально востребованных актов поведения.
\end{abstract}


Выводы: по результатам проведенного исследования можно утверждать, что правовое регулирования мер поощрения в действующем законодательстве носит фрагментарный характер. Недостаточное нормативное закрепление процедуры поощрения приводит к дестабилизации общественных отношений и снижению эффективности стимулирующей функции в целом.

Ключевые слова: санкция, поощение, стимулирование, льготы, дискреционные полномочия, государственная награда.

Цитирование. Маркунин Р. С., Мусаткина А. А. Роль поощрительных санкций в процессе правового регулирования // Legal Concept = Правовая парадигма. - 2021. - Т. 20, № 3. - C. 47-52. - DOI: https://doi.org/10.15688/1c.jvolsu.2021.3.8

\section{Введение}

На современном этапе, к сожалению, господствующее мнение по вопросу понимания санкции сводится к особенностям ее исключительно негативного воздействия на лицо, совершившее деяния, противоречащее установленным правовым нормам. При этом с латинского языка слово «санкция» имеет весьма широкое значение, но общее понимание сводится к властному и беспрекословному решению, которое имеет две стороны - негативную (в виде наказания) и позитивную (в виде поощрения). Следуя этому широкому подходу, санкцию можно определить в качестве меры воздействия на субъектов правоотношений, которая заключается в стимулировании правомерного поведения или пресечении и осуждении противоправных деяний.

В юридической науке существует подход, рассматривающий категорию санкции шире с включением не только отрицательные последствия влияния на субъект правоотношений. В результате этого сформировалось учение о поощрительных санкциях [2, с. 19]. В качестве видовой категории их следует определить как меру воздействия, связанную с наступлением благоприятных последствий для лица в связи с достижением им каких-либо значимых результатов или в качестве иных заслуг. Таким образом, в категории поощрения можно выделить ряд характерных признаков: 1) тесная связь с одобряемым и заслуженным поведением; 2) добровольность совершения правомерных деяний без императивного предписания, зафиксированного в нормативно-правовых актах; 3) результат правомерного поведения, превосходящий ожидаемый и ценный для государства и общества; 4) роль стимула по выполнению подобных действий другими лицами [1, с. 101].

\section{Место поощрительных санкций в процессе правового стимулирования}

На сегодняшний день правовая система Российской Федерации подвержена постоянным изменениям и реформированиям, которые должны затронуть систему стимулов, в первую очередь это относится к поощрительным санкциям. Они обеспечивают стабильное совершение добровольных положительных действий со стороны лиц, благодаря чему повышается активность институтов гражданского общества, происходит укрепление правопорядка и дисциплины, а также надлежащее исполнение субъектами возложенных на них обязанностей. Поощрения являются средством обеспечения реализации юридических норм и достижения социально полезных целей [5, c. 48].

Рассматривая вопрос о мерах поощрения, необходимо сразу отметить, что поощрение выступает правовым стимулом на уровне санкции правовой нормы. На сегодняшний день роль поощрительных санкций постоянно растет. Многие согласятся, что под угрозой наказания никогда не будет обеспечено стабильное, образцовое, социально полезное поведение. Наличие комплекса поощрительных санкций позволяет субъекту осознать благоприятные последствия, которые побуждают его на добровольные поступки, полезные не только для него, но государства и общества в целом. Таким образом, создается возможность достижения значимых результатов, которые превосходят ожидаемые прогнозы. Поощрительные санкции представляются индивиду наиболее значимым показателем.

Рассматривая санкции лишь в качестве мер наказания и иных ограничений, мы сознательно выстраиваем барьеры в процессе правового развития. Поощрительные же санкции 
выступают стимулом к прогрессивным действиям и иным процессам социального, в том числе правового развития [3].

Главной задачей поощрительных санкций является повышение социально полезной деятельности субъекта за счет его заинтересованности в удовлетворении своих интересов. Таким образом, происходит вытеснение негативных поступков в обществе и создается образец поведения для других лиц. Задачей норм поощрения выступает формирование у лиц интереса к совершению действий, которые в дальнейшем получают моральное или материальное одобрение [5, с. 11].

Существование поощрительных санкций не может ставиться под сомнение, поскольку, обращаясь в целом к задачам права, можно удостовериться, что они сводятся не только к наказанию лиц, совершивших противоправные действия, но и к стимулированию правомерных действий, которые осуществляются в интересах государства и общества в целом. Значимость санкции как таковой состоит не в ее негативном или позитивном характере, а в том, насколько она способна обеспечить реализацию нормы права и достижение целей права. Особенность поощрительных санкций заключается в достижении социальных целей и благ, ради которых подобная модель поведения выстраивается и стимулируется применением мер поощрения, предусмотренных поощрительной нормой права за конкретные деяния. В данном случае важно подчеркнуть, что меры поощрительного характера применяются не за правомерные поступки в целом, а именно за заслуженные действия субъектов правоотношения.

Поощрительные санкции реализуются исключительно при наличии свободной воли субъекта и отсутствии императивной модели поведения. Меры поощрения призваны заинтересовать гражданина и обеспечить совершение им положительных действий и реализацию его обязанностей. Этим поощрительные санкции отличаются от санкций негативного типа. Добровольность является ключевым элементом в поощряемом поступке, поскольку мера принуждения не столь эффективна при стимулировании лица [4, с. 106]. Лишь внешняя, формальная, реализация прав и свобод при отсутствии свободы выбора для субъекта и его внут- реннего положительного настроя не способна обеспечить требуемый результат ни для государства, ни для самой личности. В связи с этим именно дозволения активизируют комплекс побудительно-активных обеспечительных средств в правоотношениях, которые положительным образом будут сказываться на участниках. Одним их таких средств выступает поощрительная санкция [6, с. 143].

\section{Классификация поощрительных санкций и их характеристика}

Поощрительные санкции также можно подразделить на виды:

1. Санкции в виде материального поощрения. Достижение полезных результатов обеспечивается за счет предоставления материальных средств субъектам правоотношений за качественно выполненную работу. В этом виде санкции представлены целым перечнем поощрений: премия, надбавка к заработной плате, награждение ценным подарком и т. д.

2. Санкции в виде морального поощрения. Направлены на удовлетворение духовных и социальных потребностей людей. Целью выступает выражение признания человеку за его действия и повышения его авторитета среди окружающих лиц. Поощрением этого вида могут выступать: грамоты, знаки отличия, помещение фотографий на доску почета, информационные заметки в СМИ, дополнительные дни отдыха, продвижение по карьерной лестнице и т. д. У человека в результате применения данного вида поощрений наступает чувство удовлетворения от выполненной работы. Также имеет место благодарность со стороны сотрудников за поощрение, что создает стимул продолжать данный вид деятельности с большим энтузиазмом.

3. Льготы. Представляют собой определенные преимущества и дополнительные права для субъекта правоотношений. В данном случае имеются ввиду не социальные льготы, предусмотренные законодательством, а льготы дополнительного характера, устанавливаемые в индивидуальном порядке. Это является сверхмерой, в результате которой социальная защита в отношении граждан осуществляется на более высоком уровне, гарантируемом законодательством. К числу таких 
льгот можно отнести: обеспечение жильем, предоставление стоянок для транспортных средств, оплата медицинского обслуживания, организация транспортного обслуживания работников и т. д.

4. Награждение. Выступает высшей формой поощрения, которая выражается во вручении различных государственных наград в виде медалей, орденов и знаков отличия. Основанием награждения служат выдающиеся заслуги, имеющие значение для общества, государства или конкретных лиц [1, с. 101].

\section{Недостатки правового регулирования поощрительных санкций}

Многие правоведы склонны говорить о фрагментарном законодательном регулировании процесса предоставления наград и иных поощрений. В частности, рассматривая поощрительные санкции, стоит уделить внимание процессуальному аспекту их применения. Строгая процедура позволяет гарантировать своевременность, справедливость и объективность применения мер поощрения. На сегодняшний день меры поощрения лишены необходимого правового регулирования в отличии от мер наказания. В частности, наградные правоотношения регулируются в большинстве случаев министерскими инструкциями. На законодательном уровне не разработан механизм ответственности за нарушение процедуры выдачи и получения награды, что создает опасность несправедливой реализации мер поощрения со стороны государственных органов или превышения полномочий государственных служащих, в компетенцию которых входит решение вопросов подобного рода [4, с. 189]. В действующей процедуре награждения, закрепленной положением «О государственных наградах Российской Федерации», утвержденном Указом Президента РФ от 7 сентября 2010 года № 1099 (ред. от 26.10.2020) «О мерах по совершенствованию государственной наградной системы Российской Федерации», нет гарантии, обеспечивающей лицам заслуженную награду при совершении общественно полезных действий. Помимо этого, вышеназванное Положение регламентирует весьма усложненную процедуру предоставления наград с необходимостью согласования с различными органами власти, в числе которых органы местного самоуправления, главы регионов или федеральные государственные органы. В итоге награждение гражданина становится фактически невозможным.

Актуальной проблемой является также вопрос, касающийся отказов в награждении субъекта. В вышеназванном положении «О государственных наградах Российской Федерации» имеется норма, согласно которой повторное представление к награждению государственной наградой лица, в отношении которого Комиссия при президенте Российской Федерации по государственным наградам (далее - Комиссия) приняла решение о нецелесообразности награждения государственной наградой, возможно не ранее чем через год со дня его принятия. Подробную процедуру отказа в государственной награде действующее законодательство не закрепляет, а существующая практика свидетельствует об отсутствии письменного обоснования отказа в награждении. Считаем необходимым в действующем законодательстве установить требование обязательной письменной формы в случае отказа в награждении конкретного лица с обоснованием конкретных причин такого отказа. Подобная процедура будет способствовать повышению ответственности компетентных органов и сокращению проявления субъективизма с их стороны.

В рамках применения поощрительных санкций, помимо несистематизированного подхода, существует проблема с расплывчатостью терминов и неоднозначностью формулировок поощрения. Это также создает негативные последствия, а именно способствует применению поощрительных норм по воле и усмотрению вышестоящего начальства при отсутствии заранее обозначенных условий и показателей деятельности работников. При наличии подобного рода дозволений и отсутствии образцов поведения для поощрений вполне естественным выглядит усиление субъективизма и произвола в решении вопросов предоставления каких-либо льгот и награждений. Считаем, что применение мер поощрительного характера должно реализовываться согласно точному указанию юридических норм, а не за счет дискреционных полномочий компетентных должностных лиц. 
Поощрительная санкция выступает в качестве стимула к совершению положительных и одобряемых действий, за счет чего достигается планируемый результат. Одновременно с этим поощрение может реализовывать ограничивающую функцию, существенно сдерживая лицо от противозаконного, антиобщественного поведения. Помимо совершения положительных действий, поощрительная санкция стимулирует субъекты на повторяемость подобных поступков и преобразование данных актов поведения в привычку. Стоит обозначить тот факт, что, стимулируя такой вид поведения, поощрительные нормы могут одновременно обеспечивать исполнение действий, которые входят в круг юридических обязанностей субъектов, что является главным условием правомерного поведения [5, с. 46].

\section{Выводы}

1. Поощрение - особо эффективное, но крайне тонкое средство в руках правоприменителей, в связи с чем на практике использовать его необходимо исключительно на основе имеющихся результатов правовой доктрины, прибегая как к правовым, так и к моральным средствам регулирования.

2. Ошибочное применение поощрительных санкций на практике может вызвать отрицательный эффект и навредить регулируемым правоотношениям. Неверная политика в сфере применения поощрительных санкций способна вызвать нестабильность в обществе и снизить результативность данного правового стимула в целом.

3. Текущее правовое регулирование поощрительных санкций носит бессистемный характер, что не позволяет раскрыть их потенциал. Большое многообразие поощрительных норм, а также их диспозитивная основа требуют должного нормативного закрепления процедуры их реализации.

\section{ПРИМЕЧАНИЕ}

1 Статья выполнена при поддержке РФФИ, проект № 19-011-00103 А «Юридическая ответственность в правовой системе России: концепция взаимодействия, взаимосвязей и устранения противоречий с иными элементами правовой системы».
The paper was supported by RFBR, Project No. 19-011-00103 A "Legal responsibility in the Russian legal system: the concept of interaction, interrelationships and elimination of contradictions with other elements of the legal system".

\section{СПИСОК ЛИТЕРАТУРЫ}

1. Кашанина, Т. В. Санкции в праве: прошлое, настоящее, будущее / Т. В. Кашанина // Теория права. - 2019. - № 12. - С. 87-104.

2. Липинский, Д. А. Позитивная ответственность и поощрительные санкции: проблемы взаимосвязи / Д. А. Липинский // Право и политика. 2008. - № 1. - С. 19-26.

3. Малько, А. В. Льготная и поощрительная правовая политика / А. В. Малько. - СПб. : Юридический центр Пресс, 2004. - 290 с.

4. Нырков, В. В. Поощрение и наказание как парные юридические категории / В. В. Нырков. Саратов : Саратовская государственная академия права, 2006. -203 с.

5. Типикина, Е. В. Заслуга как основание для правового поощрения / Е. В. Типикина. - М. : Юрлитинформ, 2010. - $140 \mathrm{c}$.

6. Шафиров, В. М. Поощрительные санкции как средство обеспечения права / В. М. Шафиров // Поощрительные санкции в праве: реальность и юридическая конструкция : коллектив. моногр. / под ред. Н. И. Матузова, А. В. Малько. - Саратов : Саратовская государственная академия права. - 2008. - С. 138-157.

\section{REFERENCES}

1. Kashanina T.V. Sankcii v prave: proshloe, nastoyashchee, budushchee [Sanctions in Law: Past, Present, Future]. Teoriya prava [Theory of Law], 2019, no. 12, pp. 87-104.

2. Lipinskij D.A. Pozitivnaya otvetstvennost' i pooshchritel'nye sankcii: problemy vzaimosvyazi [Positive Responsibility and Incentive Sanctions: Problems of Interconnection]. Pravo i politika [Law and Politics], 2008, no. 1, pp. 19-26.

3. Mal'ko A.V. L'gotnaya i pooshchritel'naya pravovaya politika [Preferential and Encouraging Legal Policy]. Saint Petersburg, Yuridicheskij centr Press, 2004. 290 p.

4. Nyrkov V.V. Pooshchrenie i nakazanie kak parnye yuridicheskie kategorii [Encouragement and Punishment As Paired Legal Categories]. Saratov, Saratovskaya gosudarstvennaya akademiya prava, 2006. 203 p.

5. Tipikina E.V. Zasluga kak osnovanie dlya pravovogo pooshchreniya [Merit As a Basis for Legal 


\section{ГЛАВНАЯ ТЕМА НОМЕРА}

Encouragement]. Moscow, Yurlitinform Publ., 2010. $140 \mathrm{p}$.

6. Shafirov V.M. Pooshchritel'nye sankcii kak sredstvo obespecheniya prava [Incentive Sanctions as a Means of Ensuring Law]. Pooshchritel'nye sankcii v prave: real'nost' $i$ yuridicheskaya konstrukciya: kollektivnaya monografiya [Incentive Sanctions in Law: Reality and Legal Structure: Collective Monograph]. Saratov, Saratovskaya gosudarstvennaya akademiya prava, 2008, pp. 138-157.

\section{Information About the Authors}

Roman S. Markunin, Candidate of Sciences (Jurisprudence), Associate Professor, Department of Theory of State and Law, Saratov State Law Academy, Volskaya St, 1, 410056 Saratov, Russian Federation, markunin88@yahoo.com, https://orcid.org/0000-0001-7308-4848

Alexandra A. Musatkina, Candidate of Sciences (Jurisprudence), Associate Professor, Department of Constitutional and Administrative Law, Togliatti State University, Belorusskaya St, 14, 445020 Tolyatti, Russian Federation, Musatkinaaa@mail.ru, https://orcid.org/0000-0002-6974-082X

\section{Информация об авторах}

Роман Сергеевич Маркунин, кандидат юридических наук, доцент кафедры теории государства и права, Саратовская государственная юридическая академия, ул. Вольская, 1, 410056 г. Саратов, Российская Федерация, markunin88@yahoo.com, https://orcid.org/0000-0001-7308-4848

Александра Анатольевна Мусаткина, кандидат юридических наук, доцент кафедры конституционного и административного права, Тольяттинский государственный университет, ул. Белорусская, 14, 445020 г. Тольятти, Российская Федерация, Musatkinaaa@mail.ru, https://orcid.org/0000-0002-6974-082X 